\title{
Learning analytics in medical education: a turning point?
}

\author{
Melchor Sánchez-Mendiola, ${ }^{1}$ José Gerardo Moreno-Salinas, ${ }^{2}$ Tomás Bautista-Godínez² and \\ Adrián Martínez-González ${ }^{1}$ \\ ${ }^{1}$ Faculty of Medicine; ${ }^{2}$ Coordination of Open University and Distant Education. Universidad Nacional Autónoma de México. Ciudad de México, \\ Mexico
}

If you torture the data long enough, it will confess

Ronald CoAse, 2001

...the age of data analytics is upon us and medical education is lingering behind the times

TERESA CHAN, 2018

\begin{abstract}
Learning analytics is an innovative discipline that has an enormous potential to improve the quality of medical education and learning assessment. It is defined as: "the measurement, collection, analysis and reporting of data about learners and their contexts, for purposes of understanding and optimizing learning and the environments in which it occurs". In recent decades, the appearance of large volumes of data (big data), accompanied by a quick evolution of educational data mining techniques, the emergence of sophisticated technologies to analyze and visualize any type of data, as well as the availability of permanently-connected mobile electronic devices, higher processing speed and capacity of information retrieval, have generated a context that favors the use of learning analytics in clinical medicine and medical education. In this paper, the recent history of the concept of learning analytics is described, as well as its advantages and disadvantages in higher education, and its applications in the teaching of health sciences and educational assessment. It is necessary for the community of medical educators to be acquainted with learning analytics, in order to be able to integrate it to our context in an efficacious and timely manner.
\end{abstract}

KEY WORDS: Learning analytics. Big data. Educational assessment. Biomedical informatics. Data mining. Medical education.

\section{Introduction}

The large amount of data and information generated by human beings and mediated by technology has generated a setting where we must become aware of its usefulness and implications in health sciences. The availability of an enormous amount of data and powerful tools to describe, analyze, visualize and combine them has revolutionized medicine and has generated great expectations in the academic community., ${ }^{1,2}$ In parallel to the evolution of computer science and precision medicine, data mining and information processing have emerged in the field of education, with the advent of "learning analytics" (LA). ${ }^{3-5}$ This area has advanced by leaps and bounds and is transforming the education scenario, through early detection of students at risk of failure, provision of personalized education appropriate to the strengths of each student, and the ability to visualize student data in novel ways, among other possibilities. ${ }^{5-7}$

Medical education is an area of knowledge that has matured in recent decades, with windows of opportunity for the use of LA. ${ }^{8-10}$ This paper explores the origin of the concept, some of its advantages and
Correspondence:

Melchor Sánchez-Mendiola

E-mail: melchorsm@unam.mx
Date of reception: 30-10-2018

Date of acceptance: 15-11-2018

DOI: 10.24875/GMM.M19000236
Gac Med Mex. 2019;155:85-94

Contents available at PubMed www.gacetamedicademexico.com 


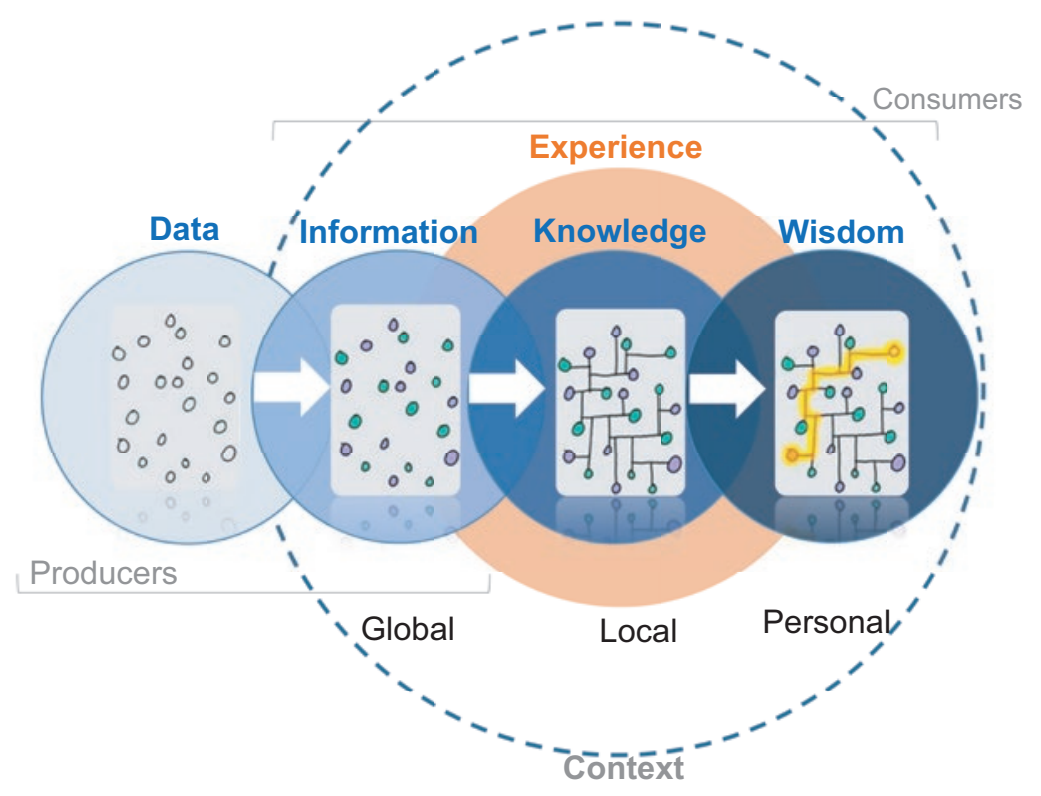

Figure 1. Hierarchy of knowledge visual interpretation (own creation).

disadvantages in modern higher education, as well as its applications in the practice of medical teaching and educational evaluation in health sciences, with the purpose to provide the general practitioner or specialist with an overview of this topic.

\section{What is learning analytics?}

\section{From data to knowledge}

We cannot conceive the world without computers or electronic devices; we are connected to the Internet at every moment and everywhere. This is how we communicate, socialize, buy and even study; "we have shifted from being analog to being digital".11 The data we digitally process are more prone to be analyzed and understood through different techniques. This is achieved with the hierarchy of knowledge (DIKW, data, information, knowledge \& wisdom), which goes from basic to complex things. ${ }^{12}$ Data is the symbolic representation of an attribute or variable; it starts being understood as information when it represents an organized set of processed data and is globally operated in an organization or community; subsequently, it escalates to the level of knowledge, which can be explained as a cognitive certainty, measurable according to the answer to why? how? when? and where?, managed at a local scope; thus, it reaches the level of wisdom, which together with experience and individual intelligence, plus consideration of previous levels of hierarchy, make it possible to reflect and obtain deeper conclusions.12 (Figure 1).

Data must be analyzed with their context, which allows processing information and holistically generating knowledge, according to the studied phenomenon. Data is one of the most valuable and strategic intangible resources, "information is power", although it should be understood as the power for a greater understanding about any system and thus promote the change towards an improvement in the system.

\section{Data evaluation in universities}

Data analysis is not exclusive to commercial organizations; universities consider data as a strategic asset in students' training processes, as well as the information and knowledge they can be obtained from them to increase retention and approval. ${ }^{4}$ Data registered by universities include those that are captured at the moment of student admission, such as academic background, socio-demographic and economic profiles, academic trajectory, number of courses, grades, use of the library, and connection to the wireless network, among others. If the university has online learning management systems, students leave "digital" prints (the fingerprint formed by the traces left when using the Internet, comments on social networks, Skype calls, use of applications, e-mail records) or traces of online activities, which would allow knowing the frequency students enter the learning platforms with and 
the time of permanence, how they express themselves in forums, the way they advance (parallel or serial) or who their contacts are; finally, the data at graduation, such as the time to get credits, final average, the option of getting a degree, etc. Universities should record student data at three moments: at admission, during their trajectory and at graduation. ${ }^{4}$

Obtaining information from data that can translate into knowledge will enable better decision making by those involved in the training process. It is important to personalize education and consider each student as a different individual, with particular needs, "we should never interact with students as if they were all the same". ${ }^{13}$

\section{The process and levels of analytics}

According to Campbell and Oblinger,${ }^{14}$ the process of analytics has five phases:

- Recording. Data are the basis of analytical efforts, in multiple sources and formats. They can originate inside or outside the institution. The management, collection, organization and rationalization of data is a considerable challenge, but it is vital because the decisions based on them depend on their quality and entirety.

- Reporting. Once the data have been extracted and stored, it is possible to make queries and reports, examine the information and identify trends, patterns and exceptions. Traditional reports (data tables) are being replaced by dashboards, which graphically display the data in comparison with the goals, and are easier to understand.

- Predicting. The collected and stored data are statistically analyzed. Model rules can be simple or complex, based on numerous data points and algorithms to generate predictions with the purpose to identify the variables that contribute to student success or risk.

- Intervening. The purpose of any analytical project is to allow an institution to act based on predictions and probabilities, by establishing lines of action to intervene to the benefit of students.

- Refining. Monitoring the impact of the project is a continuous effort, and statistical models should be periodically updated. Refinements may involve new data or process improvements.

The purpose of organizations is to obtain the best possible knowledge of their data, and therefore it is necessary to resort to advanced analyses of structured or unstructured data: ${ }^{15}$
- Descriptive analytics: It answers the question: what happened? It objectively reviews the series of historical data of a phenomenon. It uses descriptive statistics.

- Inquisitive analytics: Diagnostic process to investigate why did a phenomenon happen. It examines the descriptive results and critically evaluates the event within its context.

- Predictive analysis: It studies available data, to probabilistically predict future results, by answering the question: what is likely to happen?

- Prescriptive analytics: Optimization analytics whose objective is to guide decision making by answering the question: what should we do to achieve the objectives?

\section{Learning analytics}

LA is a relatively new concept. Among its precursors are George Siemens ${ }^{4}$ and Tanya Elias, ${ }^{16}$ who define it as "the use of intelligent data, data produced by the learner and analytical models to discover information and social connection, and to predict and advise on learning", as well as "the measurement, collection, analysis and reporting of data on students and their contexts with the purpose to understand and optimize learning and the settings where it is produced", respectively.

In 2011, the concept of LA appeared for the first time in the Horizon Report; ${ }^{17}$ since then, the concept has acquired great relevance in education (https://g.co/ trends/UBMM1). In said report, LA is referred to as the "interpretation of a large amount of data produced and collected to the benefit of students, in order to evaluate academic progress, predict future performance and detect possible problems." Data are collected from explicit student actions, such as completing assignments and taking exams, and from tacit actions, which include online social interactions, extracurricular activities, publications in discussion forums, and other activities as part of student progress.

The goal of LA is to "allow teachers and schools to adapt educational opportunities to the level of need and ability of each student in the near future." In 2011, the first World Conference on Learning Analytics \& Knowledge (LAK) was celebrated, ${ }^{18}$ where the following definition was coined:

Measurement, collection, analysis and reporting of data about learners and their contexts, for purposes of understanding and optimizing learning and the environments in which it occurs. 
$L A$ is the intersection of numerous disciplines: learning sciences, pedagogy, psychology, and web and computer science ${ }^{19}$ as well as a variety of related fields such as academic analysis and educational data mining. It gathers analytical techniques such as machine learning, data mining, information retrieval, statistics and visualization..$^{19,20}$

LA has the purpose to identify opportunities to improve the educational process and personalize the learning experience for each student, which enables minimizing the risk of dropouts. It has three fundamental products: early warnings, recommendation of courses and adaptive learning.

\section{Virtues and limitations of learning analytics in higher education}

\section{Learning analytics models}

Literature-reported LA trends in higher education correspond to alert mechanisms, algorithms, clustering, recommendation systems, adoption models and visualizers. ${ }^{21}$ However, it is important to stop along the way and reflect on criticisms, associated with the possible absence of value of the "clicks" made by the students on the conditions, operations, products, evaluations and standards, regarded as the axes of educational models. It is important not to forget that LA, in apparent tautology, is for learning, for transforming the methods by means of which this is best achieved. ${ }^{22}$

The models that prevail around LA have adopted parts of the generic analytical process, which is composed of the capture, report, prediction, action and refinement phases. This has allowed the construction of models where the participating stakeholders, the set of databases, the techniques and objectives are the substantive elements of change in the process of learning. Its communicating vessels are the students, the processes, data interpretation, and optimization of resources. In this dynamic are the Siemens ${ }^{23}$ and Chatti ${ }^{24}$ models found, which from an organic and systematic perspective have incorporated elements that might strengthen LA. We say organic and systematic because these concepts suggest the incorporation of more open and closed databases and, consequently, of a larger volume of data, to such an extent, that a point of building models on open learning analytics has been reached. ${ }^{25}$

The results of these models are often inconsistent with students' academic achievements. For this reason, education analytics is claimed to be still at an incipient stage of development, upon which highly promising expectations have been placed. ${ }^{26}$ To promote it, emphasis has been made on its integration into pedagogical models based on educational research (quantitative, qualitative and mixed), in order to improve teaching processes and strengthen learning. ${ }^{21}$

The questions proposed by McLuhan in the "global village", namely, what does the technology amplify or intensify? What does it wear down or make obsolete? What does it recover that was previously lost? How do these effects flip when the technology is pushed to its limits? ${ }^{27}$ and Bergson's ${ }^{28}$ idea about the cinema metaphor to freeze time drive us to propose a conceptual model where analytics, as a film, opens the possibility for analyzing what happens between students' states of learning. This approach allows us to introduce the concept of "becoming" in learning, since it is the continuous flow of life that is constructed building upon the relationships established by the individual with himself and his surroundings.

\section{Becoming, a missing concept in learning analytics}

What meaning do the "students' clicks" have in the construction of their knowledge? Using these "clicks" as inputs, is it possible to build alternate learning realities? We place the student in the center, with the purpose to answer these questions through the analytical model we propose. Life is movement, we educate for life. For these reasons, "becoming" is the basis upon which we build our LA model. Our approaches integrate the concepts of the creative evolution of life, developed by Henri Bergson. ${ }^{28}$ In 1907, Bergson proposed the integration of the theory of life and the theory of knowledge. Subsequently, Bautista added the accidentality dimension to this theory (Bautista, "Open the doors to humanistic systems engineering", 2018, in press), ${ }^{28}$ i.e., life's random nature (Figure 2).

The theory of life reinforces the idea that intelligence transforms and is transformed itself in the vortex of life evolution. It allows inserting ourselves in the medium under the conditions it determines. Intelligence has a past where time leaves its mark and acts in the present. In this dynamic, memory plays a substantive role: it continually accumulates each event that occurs during our existence and registers the past. It determines who we are and what we do and, in this progressive circularity, we build ourselves. Our attitude and the redirection of our attention is under 
a

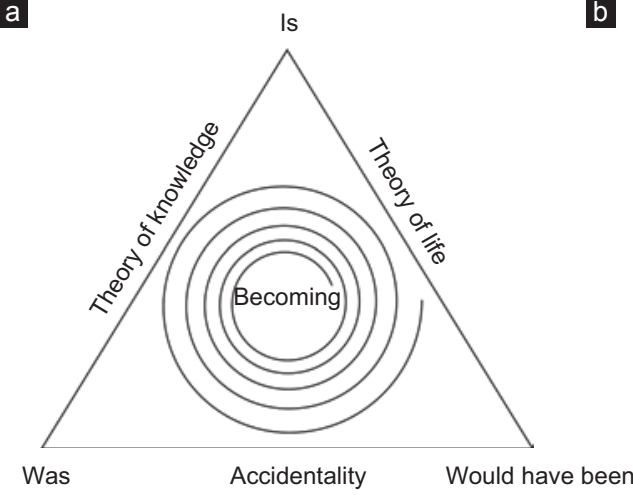

b

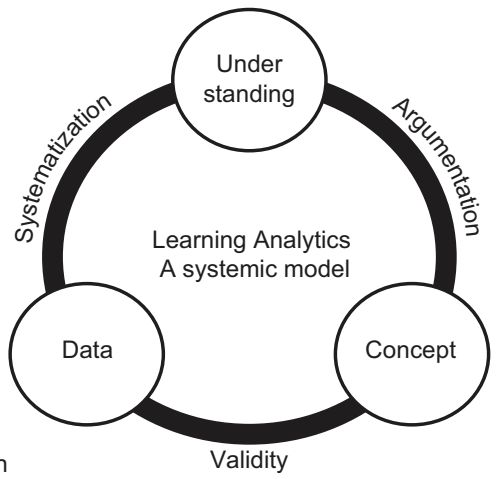

Figure 2. Framework of reference for a learning analytics from a humanistic perspective (Bautista, "Open the doors to humanistic system engineering", 2018, in press). a) Epistemological bases for the recognition of the student's life points of inflection; b) Learning analytics conceptual system.

the impulses of memory and allow us to reconfigure our actions. Intelligence, memory and duration are some concepts housed by the theory of life. This, as a complement to the theory of knowledge, gives shape to a "creative evolution", embodied in the concept of becoming. ${ }^{28}$

The vertices of the triangle (Figure 2a) are related to time manipulation: past, present and imaginary, to subsequently project them in the future, as a teleological and ethical construct. In this framework, time is a dependent variable, rather than a specific dimension through which we move across. When these vertices cross by a point of inflection in the course of life, we consider that it is "a particular moment, upon which an event narrows, where, somehow, the event must be reinterpreted again, as if it was returning in an outof-place, modified form, but forcing us to re-declare it". In short, a point is when the consequences of a construction of truth, whether political, amorous, artistic or scientific, generally force us to re-make a radical choice, as at the beginning of everything, when we accept and declare the event". ${ }^{29}$

Stopping time in life's development inflection points, in moments of apogee or crisis, becomes a transformation. Becoming is that which comes to belong to continuous movement as a result of the relationships we continuously establish with those we interact with and with our circumstances. The inflection points represent the magnetization of the event to redefine our course. Taking into account the artifice of stopping time and the vertices and edges of the creative evolution theory, it is possible to confront our state of consciousness with external things. It is the empty space where we must redefine our attitude and redirect our attention. In this case, the becoming of students, depicted in Figure 2a, is the individual's own construction based on the relationships he continuously manages to establish. We consider that it is possible to construct it based upon three axes: the data, the concept and the understanding, articulated by validity, argumentation and systematization, respectively (Figure $2 b$ ).

To deepen our understanding, we need to establish benchmarks in the past; the fixation of these points allows us to create alternate realities. We go back to uchronia's idea of alternate reality as a denial of sensitive things, in order to have an "antidote against the weight of deterministic tradition"..$^{0}$ The construction of this type of realities is necessarily situated in the inflection points the student crosses by. We achieve uchronia by integrating models centered on data, such as the one proposed by Siemens ${ }^{4}$ and the systemic model here presented. Both the one that is centered on the data and the one that allows to recognize life's points of inflection, introduce us to the process of our understanding in order to, based on it, build an alternate reality. The strata or layers we must cross in order to build our alternate reality are depicted in Figure 3.

Through two vortices, we gradually introduce ourselves to each layer. One vortex corresponds to the LA process based on data and the other corresponds to the student's analytics based on life's inflection points the student recognizes in his or her becoming. The opinion corresponds to generic expressions related to universality, which is what the individual captures of an object and what one wants to say immediately. The importance of opinion opens the door to perception; opinion is the first approach to the phenomenon. Perception is an understanding that is built 


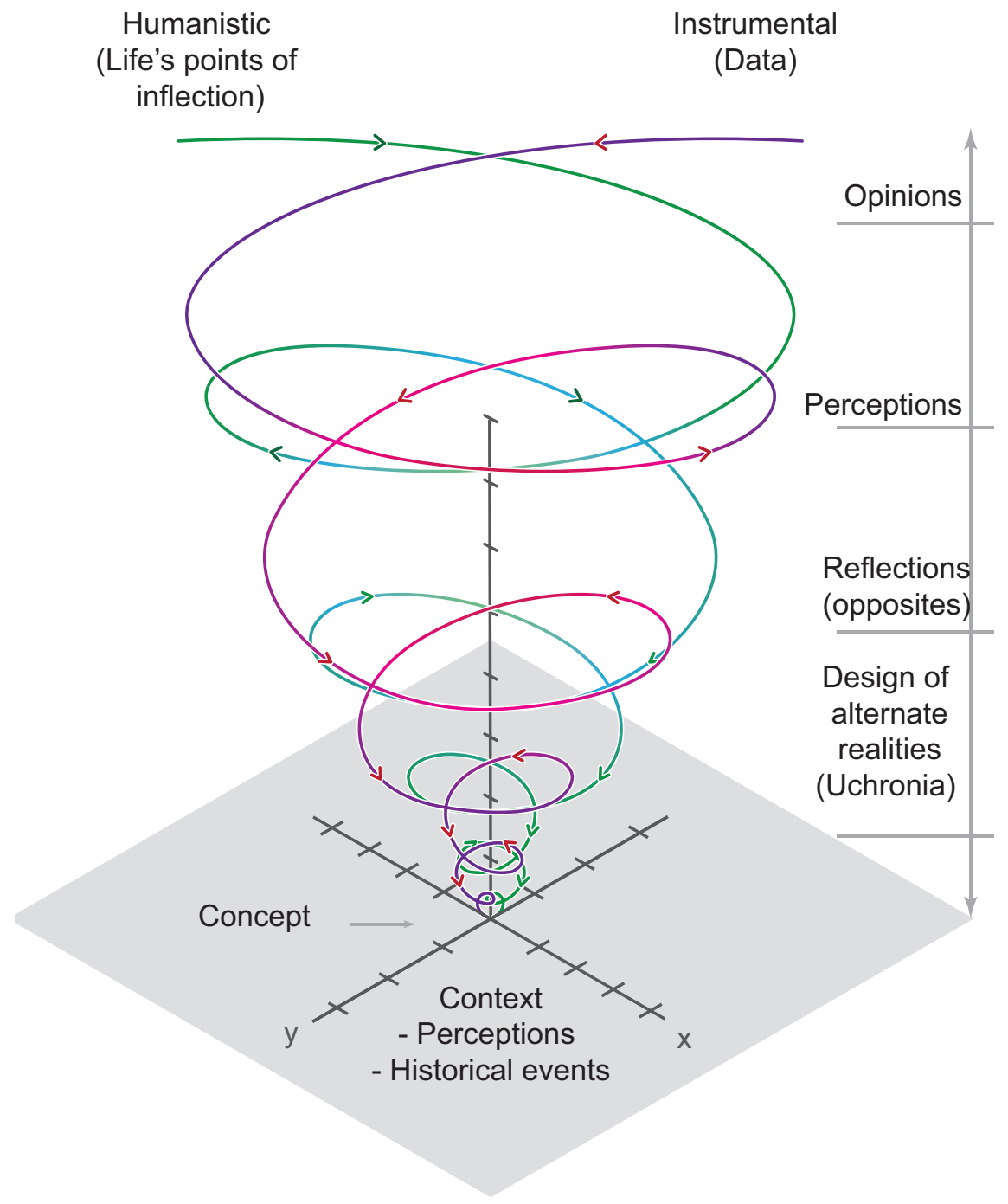

Figure 3. Learning analytics model focused on the student (Bautista, "Open the doors to humanistic systems engineering", 2018, in press).

upon opinion, and that goes through a process of conscious assimilation to determine the true things based on an exercise of personal reflection, marked by our past. Perceptions and historical events determine our reality; during the process of reflection, in a Hegelian sense, we build opposites, which allows us to create a social conscience and, in consequence, empathy.

In recent times, LA has become one of the topics of greatest interest for transforming education. Research remains in the line of analyzing more data to recognize underlying patterns that enable better decision making about learning. However, research shows inconsistencies in terms of results as well as a need for evidence on the impact on learning. For this reason, we propose a systemic model that integrates the analysis of data and life focused on the student him/herself. With this system, the student might recognize the inflection points throughout his/ her life as a student, the decisions he/she has made, the alternatives he/she could have chosen and the alternate scenarios he/she would be going through.

\section{Learning analytics applications in medical education}

The growth of data and information in clinical and educational environments constitutes an unprecedented scenario for the use of data mining and LA. ${ }^{1,2}$ 
Table 1. Learning analytics categories and techniques that can be applied in medical education (adapted from Chan')

\begin{tabular}{|c|c|c|}
\hline Category & Techniques & Examples in medical education \\
\hline $\begin{array}{l}\text { Descriptive analyses of } \\
\text { quantitative data }\end{array}$ & $\begin{array}{l}\text { Summary statistics, visual analytics, cluster analysis, } \\
\text { social network analysis, heat maps. }\end{array}$ & $\begin{array}{l}\text { - Graphs of series of average achievement scores } \\
\text { (e.g., exams and grades). } \\
\text { - Radar plots (multiple data points on grids of } \\
\text { competencies). }\end{array}$ \\
\hline $\begin{array}{l}\text { Descriptive analyses of } \\
\text { qualitative data }\end{array}$ & $\begin{array}{l}\text { Computational linguistic analyses of text coherence, } \\
\text { semantic similarity, lexical diversity, syntactic complexity. }\end{array}$ & $\begin{array}{l}\text { - Natural language processing (NLP) with artificial } \\
\text { intelligence being used. } \\
\text { - Automated content analysis, to "learn" human coding } \\
\text { across large volumes of data (e.g., flagging of } \\
\text { qualitative comments by faculty) }\end{array}$ \\
\hline Explanatory modeling & $\begin{array}{l}\text { Difficulty and learning factors, linear regression, cognitive } \\
\text { model automatization, decision trees. }\end{array}$ & $\begin{array}{l}\text { - Learning trajectories. } \\
\text { - Learning curves. } \\
\text { - Cumulative sum score plots. }\end{array}$ \\
\hline Predictive modeling & $\begin{array}{l}\text { Linear and logistic regression, nearest neighbors' } \\
\text { classifiers, Bayesian classifiers, support vector machines, } \\
\text { neural networks. }\end{array}$ & $\begin{array}{l}\text { - Prediction of difficulties in residencies (e.g., } \\
\text { remediation, probation, failure. } \\
\text { - Detection of residents' performance patterns. }\end{array}$ \\
\hline Evaluative analyses & $\begin{array}{l}\text { Several of the above-mentioned techniques, switching the } \\
\text { focus of interest from the trainee towards the residency } \\
\text { program, the faculty or the system. }\end{array}$ & $\begin{array}{l}\text { - Daily assessments of competency milestone data. } \\
\text { - Gender bias in assessments. }\end{array}$ \\
\hline
\end{tabular}

Even when the teaching and evaluation strategies we use in the health system and educational institutions have evolved and become technologized, they continue to be essentially traditional and conservative. ${ }^{31}$ Despite the rhetoric surrounding higher education, we continue to apply educational models focused on the educator rather than on the learner.

The medical teaching realm is an "ecology of learning", a system that includes factors, contexts and stakeholders that multi-dimensionally interact. This ecology encompasses teachers, learners, learning and evaluation tasks, educational materials, patients, hospitals and universities, which interact to generate formal and informal learning in students. ${ }^{32}$ In addition to this system, technological devices have been inserted in many facets of our lives, contributing to the "fingerprint", that path we leave on the network when using our personal devices. ${ }^{14}$

Medicine handles large volumes of data and information on a daily basis, which come from patients, health professionals, and hospital devices, among others. Analytics is required for these data to acquire meaning and become actionable information, otherwise they are irretrievably lost. ${ }^{2}$ These data can become reservoirs that feed into the health system and promote higher quality care. Modern research should include the new "data science" discipline, a meta-discipline that involves statistics, computer science, mathematics, data analysis and visualization, machine learning, among other concepts. ${ }^{33,34}$ This way, we could apply these tools in translational research and curricular innovation.

In the last decade, there has been an increase in publications on educational data mining and $L A,{ }^{35}$ as well as LA and medical education. ${ }^{1}$ In Medline, in 2008 there was only one reference about LA, in 2017 there were 162 and from January to October 2018 there are 225 (www.pubmed.gov), which reflects the growing interest in the subject. Some experts predict that, by the year 2022, practically all research carried out on education will somehow involve LA. ${ }^{36}$ It is pertinent to disseminate these concepts among the participants in the process of student and resident training, since with the implementation of competency-based education, reliable professional activities, progress testing, biomedical informatics, among other strategies at the global level, data on undergraduate and graduate students, patients, teachers and health systems are accumulating. These data place traditional systems of school services and educational evaluation of universities and health care centers in a difficult position for the detection of each student's competency areas in a timely manner. LA has the potential to assist educators and educational institutions in decision-making, in exploring questions at the systemic level, and in identifying problems that can be fed back into programs. ${ }^{1,4}$

There are several techniques and methodologies doctors are unfamiliar with, which can revolutionize the way we approach educational data analysis and visualization (Table 1). Recently, some institutions 
have been pioneers incorporating these methodologies. The incorporation of LA into each context should be professionally and prudently done, without overestimating its usefulness in the short term or underestimating its technical sophistication. It is fundamental to integrate the LA implementation process with a solid theoretical-conceptual educational support, otherwise there is the risk of obtaining a large amount of non-interpretable data, or data not reflecting the item that is wanted to be explored and that drive to erroneous decisions. ${ }^{37-39}$ This implies the participation of clinicians and education professionals, since in the various stages of data collection, aggregation, analysis and reporting, a comprehensive academic perspective is required.

There are reports on the use of LA for medical education in different disciplinary areas:

- Data dashboards in the teaching of emergency medicine, to describe and characterize residents' learning events. ${ }^{40}$

- Visual analytics, to use data visualization methods in the medical curricula, combining data analysis with techniques to represent knowledge and strengthen human cognitive ability to recognize visual patterns. This can help identify curricular aspects that otherwise are not visualized..$^{41,42}$

- Curriculum mapping, to describe, manage and explore study plans administrative and curricular aspects. With visual analytics, relationships between curricular elements can be discovered, and their updating and incorporation of educational innovations be facilitated, specifying curricular metadata up to the level of expected learning results. ${ }^{43}$

- Computerized facial expression recognition and its educational implications. Tools have been developed that enable identifying a wide variety of facial expressions, and their relationship with affective and emotional patterns, as well as learning "clues" and individual responses to educational challenges. ${ }^{44}$

LA has increased its popularity in education. In addition to the LAK congress, the Society for Learning Analytics Research (https://solaresearch.org) was created, with academics from different parts of the world. This group developed a journal on the subject, the Journal of Learning Analytics (https://learning-analytics.info/journals/index.php/JLA/index) and the Handbook of Learning Analytics (https://solaresearch.org/ hla-17/).

At the International Conference on Education in Residences, a Learning Analytics Summit has been included, whereby its use is legitimized (https:// icreblog.royalcollege.ca/2017/08/30/top-3-reasons-toattend-the-learning-analytics-summit-a-guest-postby-dr-rodrigo-cavalcanti/). The University of New York School of Medicine created a Learning Analytics Division at its Institute for Innovations in Medical Education (https://med.nyu.edu/institute-innovations-medical-education/) and has implemented a curriculum to train future physicians on the use of big data, using data from more than two and a half million New York patients (https://med.nyu.edu/departments-institutes/innovations-medical-education/researchscholarship/grants/health-care-the-numbers).

The Investigación en Educación Médica journal of the National Autonomous University of Mexico Faculty of Medicine published the article "Big Data and Analytics Learning in health applications and medical education, ${ }^{, 45}$ and in the curriculum of the undergraduate program of said faculty, the subject Biomedical Computer Science is included. ${ }^{46}$ In the current textbook version of this course there are chapters on analytics and computer science educational implications. ${ }^{47}$

In August 2018, an academic session was held at the National Academy of Medicine of Mexico on the subject of LA in medical education (https://bit. Iy/2NyGSG2). Currently, the creation of an Engineering and Data Science degree, as well as the Data Science specialty, are in process for their eventual approval in entities of the National Autonomous University of Mexico. In the short and medium term, the group of academics interested in these disciplines in our country will be strengthened in order to improve the quality of teaching, learning and educational evaluation.

\section{Learning analytics potential in educational evaluation}

Currently, there is a large amount of academic information on medical students. Their previous school performance, use of social networks, books read online, use of smart phones, participation in forums, time dedicated to a resource, imply an approach to understanding their behavior. The integration of these data is a key factor for a better understanding of the educational process. While some students learn in-person, others do it in a virtual or hybrid form, in small or large groups, and practically all learn in social networks. Student interactions are complex and there are ways to work these interactions, by recovering them to identify and analyze elements that can improve 
learning. Something that should be highlighted is that LA has as its fundamental purpose to help the student to participate in his or her own educational trajectory and delve into the understanding of the learning process. By identifying the students with lower probabilities of academic success through evaluation, the process could be timely modified and customized.

Evaluation is an inherent element of the teaching-learning process and assesses the students in their personal achievements at professional development phases. Greater emphasis is needed on the training function in order to promote student learning and seeking to improve different educational aspects. LA offers the possibility of having a more complete vision of all educational evaluation areas not only of students, but also of teachers, plans and study programs, study materials, medical schools and faculties, with visually presented results that generate research questions. The assessment instruments used in a conventional way to evaluate knowledge, skills, attitudes and values can be enriched by LA with new types of evaluation, such as social network analysis and discourse and conversation analysis. ${ }^{48}$ It can also be useful to improve feedback to students, their self-regulation skills and to promote better performance through training evaluation. ${ }^{49,50}$

In the LA models, the evaluation stage is not explicitly found, as observed in Siemens ${ }^{23}$ and Chatti ${ }^{24}$ works, and including it is therefore advisable. Harnessing the power of conventional evaluation plus evaluation with LA can effectively close the data cycle and enhance its performance and usefulness. Analytics potential is large and extends to all stakeholders involved in the educational process. Regarding the students, by carrying out an academic follow-up of their development plus an individualized feedback, their academic success can be increased by identifying them early. Greater learning personalization can be achieved with recommendations to the process of continuous improvement of contents by the teacher, in order for them to be more adaptable to the needs and abilities of students, by providing detailed reports on the achievement of knowledge and skills over time, comparing it with its starting point, and comparing the performance with other students or cohorts. ${ }^{49,50}$

In relation to teachers, LA can enrich the evaluation of teaching performance, in order to encourage professional development. Studying the interactions that occur between students and teachers in social learning environments in order to know their level of involvement, which student has the most influence in the group, discover communication patterns, detect which students work best together or detect isolated students. LA can reveal teaching and learning practices, evaluate the learning outcomes of a course, and detect areas that need improvement. In relation to the institution, students can be prevented from dropping out and falling behind, graduation rates can be improved, measures for academic success can be implemented, teaching can be improved by means of tools, digital resources, teacher training, and continuous update of the contents of the courses that are taught. LA can help assess programs by comparing student cohorts, offering national and international benchmarks, as well as by providing institutions with feedback on their objectives.

\section{Conclusions}

- LA is a modern strategy that involves a combination of disciplines aimed at improving the quality of education. It involves computer science, visualization and data science, as well as statistics, among others. ${ }^{51}$

- Analytics in education has had a highly important development over the last decade, with the appearance of congresses, books and journals, with original research on the subject.

- It is essential for LA to be supported by education sciences and relevant learning conceptual frameworks, in order for its use to be grounded in real educational problems.

- Its potential use in medical education is rather broad, and it requires that health professionals know the basic concepts of this area and begin to explore its use in our clinical and educational activities.

\section{References}

1. Chan T, Sebok-Syer S, Sebok-Syer S, Thoma B, Wise A, Sherbino J, Pusic M. Learning analytics in medical education assessment: the past, the present, and the future. AEM Educ Train. 2018;2:178-187.

2. Krumholz HM. Big data and new knowledge in medicine: the thinking, training, and tools needed for a learning health system. Health Aff (Millwood). 2014;33:1163-1170.

3. Lodge JM, Corrin L. What data and analytics can and do say about effective learning? Npj Sci Learn. 2017;2:5.

4. Lang C, Siemens G, Wise A, Gašević D. Handbook of Learning Analytics. EE. UU.: Society for Learning Analytics Research; 2017.

5. Greller W, Drachsler H. Translating learning into numbers: a generic framework for learning analytics. J Educ Techno Soc. 2012;15(42): 42-57.

6. Sclater N, Peasgood A, Mullan J. Learning analytics in higher education. A review of UK and international practice. Full Report. Reino Unido: Joint Information Systems Committee; 2016.

7. Bienkowski M, Feng M, Means B. Enhancing teaching and learning through educational data mining and learning analytics. An Issue Brief. EE. UU.: United States Department of Educational Technology; 2012. 
8. Lee K, Whelan JS, Tannery NH, Kanter SL, Peters AS. 50 years of publication in the field of medical education. Med Teach. 2013;35(7): 591-598.

9. Ellaway RH, Pusic MV, Galbraith RM, Cameron T. Developing the role of big data and analytics in health professional education. Med Teach. 2014;36:216-222.

10. Cirigliano MM, Guthrie C, Pusic M V, Cianciolo AT, Lim-Dunham JE Spickard A, et al. Exploring the future of learning analytics in medical education. Teach Learn Med. 2017;29:368-372.

11. Hilbert M, López P. The world's technological capacity to store, communicate, and compute information. Science. 2011;332:60-65.

12. Rowley J. The wisdom hierarchy: representations of the DIKW hierarchy J Inf Sci. 2007;33:163-180.

13. Bhansali N. Data governance. Creating value from information assets. EE. UU.: CRC Press; 2013.

14. Campbell JP, DeBlois PB, Oblinger DG. Academic analytics: a new tool for a new era. Educause Rev. 2007;42:40-57.

15. Mousannif $H$, Sabah $H$, Douiji $Y$, Sayad $Y$ O. From big data to big projects: a step-by-step roadmap. En: 2014 International Conference on Institute of Electrical and Electronics Engineers. EE. UU.: Future Internet of Things and Cloud; 2014.

16. Elias T. Learning analytics: definitions, processes and potential. EE. UU.: 2011.

17. Johnson L, Smith R, Willis H, Levine A, Haywood K. The 2011 Horizon Report. EE. UU.: The New Media Consortium; 2011.

18. Society for Learnig Analytics Research. [Sitio web]. International Conference on Learning Analytics \& Knowledge (LAK). Disponible en: https:// solaresearch.org/events/lak.

19. Dawson S, Gasevic D, Siemens G, Joksimovic S. Current state and future trends: a citation network analysis of the learning analytics field. En: Proceedings of the Fourth International Conference on Learning Analytics \& Knowledge. EE. UU.: ACM; 2014

20. Chatti MA, Lukarov V, Thus $\mathrm{H}$, Muslim A, Yousef AMF, Wahid U, et al. Learning analytics: challenges and future research directions. 2014.

21. Leitner $\mathrm{P}$, Khalil $\mathrm{M}$, Ebner $\mathrm{M}$. Learning analytics in higher education: a literature review. En: Peña-Ayala A, editor. Learning analytics: fundaments, applications, and trends. Suiza: Springer International Publishing; 2017.

22. Gašević D, Dawson S, Siemens G. Let's not forget: learning analytics are about learning. TechTrends. 2015;59:64-67.

23. Siemens G. Learning analytics. The emergence of a discipline. Am Behav Sci. 2013;57:1380-1400.

24. Chatti MA, Dyckhoff AL, Schroeder U, Thüs $H$. A reference model for learning analytics. IJTEL. 2012;4:318-331.

25. Chatti M A, Muslim A, Schroeder U. Toward an open learning analytics ecosystem. En: Big data and learning analytics in higher education. Suiza: Springer; 2017

26. Wilson A, Watson C, Lynn T, Drew V, Doyle S. Learning analytics: challenges and limitations. Teaching in Higher Education. 2017;22: 991-1007.

27. Wikipedia. The Free Encyclopedia. Global village. Disponible en: https:// en.wikipedia.org/wiki/Global_village.

28. Bergson H. La evolución creadora. Argentina: Cactus; 2007.

29. Badiou A. Elogio al amor. Argentina: Paidós; 2011.
30. Murcia-Carbonell A. La ucronía intencional como relato moral. España: Asociación Cultural Xatafi; 2009

31. Sánchez-Mendiola M. Educación médica basada en evidencias, ¿ser o no ser? Inv Ed Med. 2012;1:82-89.

32. Ringsted C, Hodges B, Scherpbier A. "The research compass": an introduction to research in medical education: AMEE Guide No. 56. Med Teach. 2011;33:695-709.

33. Donoho D. 50 years of data science. J Comput Graph Stat. 2017;26:745-766.

34. Altman RB, Levitt M. What is biomedical data science, and do we need an annual review of it? Annu Rev Biomed Data Sci. 2018;1:i-iii.

35. Calvet-Liñán $L$, Pérez $A A$. Educational data mining and learning analytics: differences, similarities, and time evolution. RUSC. 2015;12:98-112.

36. Larusson JA, White B. Learning analytics from research to practice. EE. UU.: Springer; 2014.

37. Cirigliano MM, Guthrie C, Pusic MV, Cianciolo AT, Lim-Dunham JE, Terry $\mathrm{V}$, et al. "Yes, and ..." exploring the future of learning analytics in medical education. Teach Learn Med. 2017;29:368-372.

38. Ellaway RH, Topps D, Pusic M. Data, big and small: emerging challenges to medical education scholarship. Acad Med. 2018.

39. Wise AF, Shaffer DW. Why Theory matters more than ever in the age of big data. J Learn Anal. 2015;2:5-13.

40. Chan TM, Sherbino J, Mercuri M. Nuance and noise: lessons learned from longitudinal aggregated assessment data. J Grad Med Educ. 2017;9:724-729.

41. O'Donoghue SI, Baldi BF, Clark SJ, Darling AE, Hogan JM, Kaur S, et al. Visualization of biomedical data. Annu Rev Biomed Data Sci. 2018;1:275-304.

42. Vaitsis C, Nilsson G, Zary N. Visual analytics in healthcare education: exploring novel ways to analyze and represent big data in undergraduate medical education. PeerJ. 2014;2:e683.

43. Komenda $M$, Víta $M$, Vaitsis $C$, et al. Curriculum mapping with academic analytics in medical and healthcare education. PLoS One. 2015;10:e0143748.

44. Littlewort G, Whitehill J, Wu T, Fasel I, Frank M, Movellan J, et al. The Computer Expression Recognition Toolbox (CERT). Face and Gesture. 2011.

45. Peñaloza-Báez MJ. Big data y analítica del aprendizaje en aplicaciones de salud y educación médica. Inv Ed Med. 2017;7:61-66.

46. Sánchez-Mendiola M, Durante-Montiel I, Morales-López S, Lozano-Sánchez R, Martinez-González A, Graue-Wiechers E. Plan de estudios 2010 de la Facultad de Medicina de la Universidad Nacional Autónoma de México. Gac Med Mex. 2011;147:152-158.

47. Sánchez-Mendiola M, Martínez-Franco Al. Informática Biomédica. México: Universidad Nacional Autónoma de México/Elsevier; 2018.

48. Martin F, Ndoye A. Using Learning analytics to assess student learning in online courses. Journal of University Teaching \& Learning Practice. 2016;13.

49. Gikandi JW, Morrow D, Davis NE. Evaluación formativa en línea en la educación superior: una revisión de la literatura. Comput Educ. 2011;57:2333-2351.

50. Ellis C. Ampliar el alcance y aumentar la utilidad del análisis de aprendizaje: el caso para el análisis de evaluación. Br J Educ Technol. 2013; 44:662-664.

51. Aikat J, Carsey TM, Fecho K, Jeffay K, Mucha PJ, Ahalt SC, et al. Scientific training in the era of big data: a new pedagogy for graduate education. Big Data. 2017;5:12-18. 